\title{
INFÂNCIA, TEMPO E ESCOLARIZAÇÃO: APROXIMAÇÕES SOBRE O TEMA NO BRASIL E NA ARGENTINA*
}

\author{
Carina Viviana Kaplan ${ }^{1}$ \\ Magda Sarat ${ }^{2}$
}

\begin{abstract}
RESUMO: Resultado de pesquisa em parceria binacional (Brasil e Argentina), este texto objetiva apresentar algumas aproximaçóes teóricas acerca das relaçóes entre tempo de escolarização e infância, priorizando os sistemas educativos argentino e brasileiro. Concebe-se a infância como um período de especificidades próprias e categoria social construída historicamente. Assim, destaca-se o tempo no processo de escolarização, o qual transforma crianças em alunos e alunas, especialmente na infância, percebida como momento oportuno para a formação individual e coletiva, em todos as sociedades.
\end{abstract}

Palavras-chave: Tempo. Infância. Escolarização. Norbert Elias.

\footnotetext{
*Este trabalho integra reflexôes do projeto binacional dos Centros Associados para o Fortalecimento da Pós-Graduação Brasil-Argentina (CAFP-BA)/Coordenação de Aperfeiçoamento de Pessoal de Nível Superior (CAPES)/Secretária de Políticas Universitárias (SPU) "Pesquisas em Educação no Brasil e na Argentina: Desigualdades Sociais, Subjetividade, Diversidade e Fronteiras”, da Universidade de Buenos Aires (UBA) e Universidade Federal da Grande Dourados (UFGD).

${ }^{1}$ Universidade de Buenos Aires, Consejo Nacional de Investigaciones Científicas y Técnicas - Buenos Aires, Argentina. E-mail: kaplancarina@gmail.com

${ }^{2}$ Universidade Federal da Grande Dourados, Faculdade de Educação - Grande Dourados (MS), Brasil.E-mail: magdaoliveira@ufgd.edu.br
}

DOI: $10.1590 /$ CC0101-32622017173657 


\title{
Childhood, time and schooling: approximation on the topic in Brazil and in Argentina
}

\begin{abstract}
A result of a research in a binational partnership (Brazil and Argentina), this text aims to present some theoretical approximations about the relations between schooling time and childhood, prioritizing the Argentinean and Brazilian education systems. Childhood is conceived as a period of one's own specificities and a social category built historically. Thus, time in the process of schooling is highlighted, when it transforms children in students, particularly during childhood, seen as a timely moment for human, individual and collective formation, in all societies.
\end{abstract}

Keywords: Time. Childhood. Schooling. Norbert Elias.

O relógio no pátio da escola [...] indicava "atrasado". No corredor penetravam murmúrios de consultas secretas vindos das portas das salas de aula. Atrás delas, professores e alunos eram camaradas [...]. Foi assim que violei meu dia que mal começara, e entrei. Ninguém parecia me conhecer. [...] Também o professor retivera meu nome desde o início da lição. Não deveria mais ser chamado. Quieto, ocupei-me até o toque da sineta. Mas foi tudo em vão. (BENJAMIN, 1993, p 83-84)

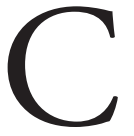

onvida-nos Walter Benjamin a pensar a relação que a criança tem com o tempo, a escola e seus símbolos, demonstrando o modo como se configuram os espaços entre adultos e crianças no cotidiano escolar. Partindo dessa premissa, este trabalho apresenta uma série de aproximaçóes teóricas sobre as relaçóes entre tempo de escolarização e figuras da infância, priorizando seus lugares nos contextos legais do sistema educativo argentino e brasileiro, ênfases deste recorte, que faz parte de uma investigação mais ampla.

A condição de meninos e meninas e a condição de aluno estão imbricadas reciprocamente nas concepçóes teóricas e no plano das políti- 
cas e normas estatais, apontando um lugar simbólico que é concedido às infâncias e aos seus destinos nos dois países.

Historicamente, a sociedade ocidental, a princípio, assimilou a figura da criança como um adulto em miniatura, até o momento em que socialmente passou a interpretar a infância como um universo autônomo, com características intrínsecas e específicas. $\mathrm{Na}$ modernidade, a infância adotou um estatuto próprio, com uma idade diferenciada da vida adulta, e instituiu-se também um tempo para a escola (OLIVEIRA; SARAT, 2009).

O que significa um tempo de escola para a infância? Tal é a pergunta sobre a qual nos debruçamos, pois sabemos o significado do tempo na vida das crianças e o lugar que a escola ocupa. Ela passa da condição de criança para a condição de aluna - nos diferentes contextos sociais - em um tempo curto, considerando as sociedades ocidentais mais complexas, nas quais o início da escolarização se dá nos primeiros anos de vida.

Atualmente, as crianças são institucionalizadas muito cedo. Em geral, temos enviado as crianças pequenas às escolas, pré-escolas e creches, a depender das legislaçóes que normatizam o tempo da licença-maternidade para as mães trabalhadoras.

No Brasil, isso acontece a partir dos 6 meses, de acordo com a Lei $n^{\circ}$ 11.770, de 9 de setembro de 2008 (BRASIL, 2008). Na Argentina, estipula-se a idade de 3 meses, conforme a Lei no 20.744 . Tais dados indigitam as políticas públicas de atendimento à infância nos dois países. Para outros países, citamos: "Alemanha: 14 semanas; Austrália: 52 semanas; Chile: 18 semanas; Egito: 1 mês e 20 dias; Estados Unidos: 12 semanas; Eslováquia: 7 meses; Líbano: 7 semanas; Quênia: 2 meses; Suécia: 64 semanas (a licença pode ser dividida entre os pais)" (DIVISÃO DE ESTATÍSTICAS DAS NAÇÕES UNIDAS, 2005 apud MELLO, 2016).

A instituição educacional é um espaço criado socialmente, assim como os contextos familiares, e configura-se em especificidades próprias, atingindo todas as crianças nos primeiros anos de vida. Não é o foco deste artigo, mas temos avançado na reflexão sobre os bebês na educação infantil, investigando sua inclusão como crianças e não como alunos, sujeitos a práticas pedagógicas escolarizadas. 
Podemos dizer que, de forma relativamente naturalizada, concebemos nas sociedades atuais "a invenção da forma escolar como um modo de socialização escolar [que] se impôs a outros modos de socialização com tudo o que faz parte dessa configuração histórica e singular" (LAHIRE; THIN, 2001, p. 11). As crianças são parte dessa invenção social - a escola, uma configuração que se constitui por meio de relaçóes pedagogizadas e disciplinadoras, pautadas em modelos escolares. Como estudantes, elas participam — as crianças — de uma configuração organizada, em sistemas de ensino, a exemplo, no caso deste texto, do que se pratica nos países citados, Brasil e Argentina.

\section{O TEMPO E A CRIANÇA}

O tempo representa um dos símbolos sociais mais significativos da condição humana nos processos de individualização e de aprendizagem do social. Ele não é um dado objetivo ou subjetivo, mas social, e um instrumento de orientação que só pode ser interpretado se levarmos em conta que é transmitido como parte de um acervo do saber social — processos sociais de longa duração, na concepção de Norbert Elias — que se aprende em cada geração.

Desse modo, mais que um dado objetivo ou um dado a priori, o tempo constitui-se como uma referência simbólica que vai sendo transmitida e aprendida de geração em geração, por intermédio de um processo complexo e profundo. A aprendizagem do tempo ocupa um lugar central na produção subjetiva da experiência individual e coletiva da infância:

Toda criança vai se familiarizando com o "tempo" como símbolo de uma instituiçáo social cujo caráter coercitivo ela experimenta desde cedo. Se, no decorrer de seus primeiros dez anos de vida, ela não aprender a desenvolver um sistema de autodisciplina conforme essa instituição, se não aprender a se portar e a modelar sua sensibilidade em função do tempo, ser-lhe-á muito difícil, senão impossível, desempenhar o papel de um adulto no seio dessa sociedade. (ELIAS, 1998a, p. 13-14) 
O tempo experimenta-se como uma força que nos coage biograficamente e, por sua vez, é um meio de orientação para a existência coletiva, determinando, por exemplo, o calendário acadêmico, os anos de escolarização e as idades específicas para os diversos níveis do sistema educativo. Tais conceitos podem ser pensados como símbolos do acervo cultural das sociedades contemporâneas.

A escola, com seu tempo e lugar específicos, refere-se ao período da escolarização e remete-nos indubitavelmente à memória social, às transformações da época e às lutas simbólicas pela conquista dos direitos da infância nos países latino-americanos, onde sabemos que nem todos os meninos e meninas usufruem os mesmos benefícios e os mesmos direitos no espaço e no mercado educativo.

Continuando a falar da questão do tempo, interrogamo-nos, pensando em uma perspectiva de longa duração, sobre como seria a construção social de um tempo de escolarização para a infância, considerando-se todas as crianças. Partimos do pressuposto de que o macrocosmo do grupo (a classe social a que a criança pertence) e o microcosmo do sujeito particular (as estratégias familiares em relação à escolarização dos filhos) dependem de uma estrutura reciprocamente organizada, que permitirá a ascensão da infância no espaço social do tempo institucionalizado ou escolarizado.

Norbert Elias (1998a) coloca em destaque os modos como as sociedades complexas lidam com o saber sobre o calendário e os relógios, concebendo-os como meios para as relaçôes humanas e para que o indivíduo se oriente acerca de si mesmo, da sua idade ou da sua etapa evolutiva. Esses aspectos estão normalizados na estrutura do sistema educativo, por exemplo, e, com o aprendizado, convertem-se em algo evidente sobre o qual apenas alguns membros da comunidade costumam refletir. $\mathrm{O}$ fragmento de Benjamim citado anteriormente aponta para a apreensão desse símbolo social, ao mencionar "o relógio no pátio..." (BENJAMIM, 1993, p. 83). A indicação de atraso no relógio será o mediador da relação com colegas, professores e atividades.

Tal processo de naturalização na vida cotidiana não oculta o fato de que a estrutura de uma sociedade, que possui uma imprescindível e inevitável rede de determinaçóes temporais, e a estrutura de uma personalidade, 
que tem interiorizada uma disciplina do tempo, imbricam-se mutuamente. Conforme aponta Elias (1998a, p. 15), "o indivíduo ao crescer aprende a interpretar os sinais temporais usados em sua sociedade e a orientar sua conduta em função deles”. Só assim ele poderá inserir-se socialmente.

Esse conhecimento internalizado é parte de sua constituição, assumindo o aspecto de uma segunda natureza. Portanto, submetemonos à necessidade de responder a pressóes como o tempo para ingressar na escola, alfabetizar-nos, seguir o caminho pré-fixado de graus e níveis de ensino, o tempo para terminar o processo de escolarização da educação formal e responder, socialmente, quanto ao que a família e a escola esperam de crianças e jovens.

Para a sociologia do tempo, esse é um dado social e um instrumento de orientação cuja matriz de constituição se finca na aprendizagem e na transmissáo geracional da cultura, e o tempo constitui uma série de ferramentas que os seres humanos construíram para desempenhar funções concretas. Em um processo de longa duração, avançamos e complexificamos as relaçóes humanas, construindo símbolos que nos remetem à medição do tempo como gesto necessário para a regulação interna e externa dos grupos humanos. Aprender sobre o tempo, além de ser um processo social, leva tempo.

Uma criança que cresce numa dessas sociedades nacionais do século XX, industrializadas e submetidas a uma regulação temporal muito intensa, requer sete a nove anos para aprender a dizer as horas, isto é, para saber ler e interpretar o complexo sistema simbólico dos relógios e do calendário, além de adaptar a ele sua sensibilidade [e] seu comportamento (ELIAS, 1998a, p. 112).

Nas sociedades complexas e industrializadas, o tempo, concretamente, é percebido e manifesta-se nas aprendizagens da infância e da vida das crianças, que fazem parte dos nossos sistemas educacionais. Suas idades são reguladas por uma convenção legal que normatiza até quando viverão sua infância e sua adolescência. As legislaçóes do Brasil e da Argentina convencionam esse tempo nessas sociedades contemporâneas. 
No Brasil, o Estatuto da Criança e do Adolescente (ECA - Lei no 8.090/90), estipula no artigo 2: "Considera-se criança, para os efeitos desta Lei, a pessoa até doze anos de idade incompletos, e adolescente aquela entre doze e dezoito anos de idade" (BRASIL, 1990).

$\mathrm{Na}$ Argentina, a Lei no 26.061, de Protección Integral de los Derechos de Niñas, Niños y Adolescentes (Proteção Integral dos Direitos de Meninas, Meninos e Adolescentes) (2005), informa, em seu artigo 20: "Es de aplicación obligatoria en las condiciones de su vigencia en todo acto [...] que se adopte respecto de las personas hasta los dieciocho años de edad".

Nessa perspectiva, estamos em condições de sustentar que as disputas de significado sobre a construção social das infâncias giram em torno do lugar que a criança ocupa na esfera estatal, familiar, nos processos de transmissão intergeracional da cultura e no tempo de cuidado de meninos e meninas e sua educação.

\section{A INFÂNCIA E A ESCOLARIZAÇÃO NA LEI: BRASIL E ARGENTINA}

A educação de meninos e meninas é definida socialmente pela família e pelos Estados, embora os contextos de desigualdades estejam presentes, impedindo que certo número de crianças tenha acesso às instituiçóes educativas. No entanto, as legislaçóes dos dois países asseveram a necessidade de investimento em políticas públicas que responsabilizem os Estados quanto aos investimentos em educação, especialmente na educação inicial.

Em artigo conjunto acerca de parcerias bilaterais, dirigentes brasileiros e argentinos afirmam que "Brasil e Argentina têm visões convergentes no campo educacional. Compartilhamos a convicção de que educação é investimento, e não gasto, e que baixos níveis de escolaridade comprometem severamente a coesão social" (HADDAD; FILMUS, 2005, p. 1).

No Brasil, tal responsabilidade está prevista na Constituição Federal. Em seu artigo 205 reconhece que a "educação [é] direito de todos e dever do Estado e da família” (BRASIL, 1988). Na Argentina, está prevista a Lei de Educação Nacional no 26.206, que, no Artigo 4o, estipula: "El Estado Nacional [...] tienen la responsabilidad principal e 
indelegable de proveer una educación integral, permanente y de calidad para todos/as los/as habitantes de la Nación [...] con la participación [...] y las familias" (ARGENTINA, 2006).

Antes de adentrar na responsabilidade que o Estado tem sobre as políticas de educação, indicaremos o lugar das configurações familiares na decisão acerca da educação das crianças. Tal aspecto foi apontado por Elias (1998b), ao estudar o curso do processo civilizatório e dos vínculos entre pais e filhos, que colocou em evidência a constante relação de dominação, sempre presente, de pais sobre os filhos. Segundo esse autor, historicamente, houve uma desigual distribuição de poder, considerando que são os pais que têm mais oportunidades de exercê-lo sobre os filhos e sua educação.

Nesse sentido, nas relaçóes entre pais e filhos, ao longo do processo civilizatório, a concepção de infância e o status dado às crianças pela família foram determinantes, a levarmos em conta sua maior ou menor autonomia e seu reconhecimento como um grupo social com características próprias. Elias (1998b) assinala ainda o problema dos pais perante o dilema de como ajudar os filhos a viver o inevitável processo civilizador individual, no qual a escola está presente, sobretudo nas sociedades ocidentais e, especificamente, nos países objeto deste estudo.

Nessa análise, colocamos também em relação recíproca as transformaçōes e as estruturas estatais e familiares, pois são ambos — Estado e família - instituiçōes das quais as crianças fazem parte, constituindo-se como indivíduos e permitindo a continuidade geracional. Para tanto, inspiramo-nos em Bourdieu (1997), que define o conceito — por vezes naturalizado - de família em um espaço no qual seus membros, adultos e crianças, convivem, decidem e medem forças, em uma configuração socialmente estabelecida.

La familia, como categoría social objetiva (estructura estructurante) es el fundamento de la familia como categoría social subjetiva (estructura estructurada), categoría mental que constituye el principio de miles de representaciones y de acciones (matrimonios por ejemplo) que contribuyen a reproducir la categoría social objetiva [...]. La sintonía casi perfecta que se establece entonces entre las categorías subjetivas y las categorías objetivas 
fundamenta una experiencia del mundo como evidente [...]. Y nada parece más natural que la familia: esta construcción social arbitraria parece situarse del lado de lo natural y de lo universal (BOURDIEU, 1997, p. 130).

Assim, os problemas concernentes à socialização e à micropolítica escolar inscrevem-se nos processos mais amplos que a legislação abarca, instituindo as políticas públicas para a infância e suas famílias. O lugar da infância e das famílias nas políticas sociais vem sendo discutido, nas últimas décadas, em diversos países da América Latina, demandando esforços para cumprir agendas que permitam incluir e compreender todos os contextos de escolarização e atendimento para crianças, adolescentes e jovens e suas famílias.

$\mathrm{Na}$ Argentina, particularmente nas últimas décadas, tem sido relevante a defesa dos direitos da infância e da sua educação, percebida nos avanços da legislaçáo para crianças e adolescentes. Em 2005, por exemplo, foi promulgada a já referida Ley de Protección Integral de los Derechos de Niñas, Niños y Adolescentes (ARGENTINA, 2005).

No ano seguinte, foi sancionada a Lei de Educação Nacional Argentina, promulgada em 27 de dezembro de 2006, sob o no 26.206, vigente até o momento. Em seu artigo 20, diz: "La educación y el conocimiento son un bien público y un derecho personal y social, garantizados por el Estado" (ARGENTINA, 2006). Portanto, ao estabelecer a educação e o conhecimento como bens públicos e direitos, o Estado é responsável para garantir seu provimento.

$\mathrm{Na}$ mesma direção, da preservação do bem público e do estado de direito na Lei no 26.206, da Educação Nacional Argentina, fica expresso no artigo $10^{\circ}$ : "El Estado Nacional no suscribirá tratados bilaterales o multilaterales de libre comercio que impliquen concebir la educación como um servicio lucrativo o alienten cualquier forma de mercantilización de la educación pública” (ARGENTINA, 2006). O Estado Nacional compromete-se, assim, com políticas que não impliquem conceber a educação com base em modelos de mercantilização da educação pública, garantindo, antes, a todos o direito de acesso.

Ainda, no sistema educacional argentino, a obrigatoriedade escolar a todo o país estende-se desde a idade de 5 anos até a finalização do 
nível de educação secundária. A estrutura do sistema educativo nacional argentino compreende, pois, quatro níveis: a educação inicial, a educação primária, a educação secundária e a educação superior, bem como oito modalidades: educação técnica profissional, educação artística, educação especial, educação permanente de jovens e adultos, educação rural, educação intercultural bilíngue, educação em contextos de privação de liberdade e educação domiciliar e hospitalar.

Destacamos ainda, na referida Lei de Educação Nacional, seu artigo $18^{\circ}$, que reconhece: "La Educación Inicial constituye una unidad pedagógica y comprende a los/as nińos/as desde los cuarenta y cinco (45) días hasta los cinco (5) años de edad inclusive, siendo obligatorio el último ańo" (ARGENTINA, 2006). Ou seja, meninos e meninas argentinos, desde os 45 dias até os 5 anos de idade, podem ser institucionalizados, e o quinto ano tem caráter obrigatório.

Nessa perspectiva da obrigatoriedade, o Estado Nacional informa também, em seu artigo 19: "El Estado Nacional, las Provincias y la Ciudad Autónoma de Buenos Aires tienen la obligación de universalizar los servicios educativos para los/as niños/as de cuatro (4) años de edad" (ARGENTINA, 2006). Ainda, é obrigação universalizar os serviços educativos para todas as crianças.

No ano de 2016, foi promulgada a Lei no 27.045, que declara obrigatória a educação inicial para crianças em todo o sistema educativo nacional argentino (ARGENTINA, 2016). Destacamos ainda a contribuição normativa, que constitui como caráter obrigatório a educação secundária, colocando-a como uma unidade pedagógica e organizativa destinada a adolescentes e jovens que cumpriram a educação primária.

No Brasil, são diversas as aproximações com as legislações argentinas das quais temos conhecimento. A educação infantil garante às crianças menores de 5 anos, em todos os documentos legais, o direito às instituiçôes de atendimento. Enfatizamos que desde a promulgação da Lei de Diretrizes e Bases da Educação Nacional no 9.394/96 (BRASIL, 1996), que normatizou a educação brasileira, tivemos avanços e retrocessos e sofremos ataques pontuais que ainda demandam envolvimento da sociedade civil para garantir o direito das crianças. 
Destacamos aqui o ano de 2016, no qual celebramos dez anos da promulgação da Lei do Fundamental de Nove Anos, ou seja, a Lei no 11.274, de 6 de fevereiro de 2006, que "estabelece as diretrizes e bases da educação nacional, dispondo sobre a duração de 9 (nove) anos para o ensino fundamental, com matrícula obrigatória a partir dos 6 (seis) anos de idade" (BRASIL, 2006).

Ao refletirmos acerca do tempo para a escolarização, essa legislação incide de forma pontual e crucial na educaçáo das crianças brasileiras. Tal legislação, ao acrescentar um ano para as crianças do Ensino Fundamental, retirou, nesse ano, as crianças menores de 6 anos da Educação Infantil. Assim, as crianças de 6 anos foram incluídas no Ensino Fundamental obrigatório, o que, na nossa concepção, promoveu um questionável processo de entrada precoce das crianças menores no ensino regular.

Nesse contexto, o tempo da Educação Infantil passou a ser o tempo da escolarização formal, com propostas muito diversas, em todos os sentidos, das práticas pedagógicas voltadas às crianças pequenas, principalmente se consideramos os menores de 3 anos. A ludicidade e a brincadeira, presentes como linguagem prioritária da infância e da Educação Infantil, vão sendo substituídas por uma perspectiva escolarizada, calcada em currículos e propostas de aprendizagens precoces para crianças de 5 e 6 anos. Inauguramos um lugar chamado escola, com tempos, espaços, linguagens, modelos e trajetórias para crianças muito pequenas, que estão iniciando sua educação formal.

Os avanços apresentados pela legislação dos sistemas de ensino no Brasil e na Argentina, ainda que tenhamos motivos para celebrá-los, ficam à mercê das mudanças políticas e econômicas, que se têm pautado por outras concepçóes de educação, ameaçando alguns direitos já conquistados. Sabemos dos retrocessos, das limitaçôes e da distância que há entre a lei e as açóes concretas de implantação, mas nesse momento não é possível aprofundar a análise, o que nos instiga às investigaçóes em parceria.

\section{A ESCOLA DA INFÂNCIA: TEMPOS E TRAJETÓRIAS}

O título do texto de Benjamin - "Chegando atrasado" que encabeça este artigo nos coloca de frente para um espaço social no 
qual a trajetória temporal é elemento constitutivo da socialização e da subjetivação escolar do indivíduo. O lugar social da escola vem sendo determinado e construído com base em dois aspectos: por um lado, as especificidades concretas e particulares dos seus contextos internos e organizativos; por outro lado, as diversas maneiras de se sentir estudante, vinculadas com as próprias condições da existência dos indivíduos, que são as origens sociais, os vínculos familiares, os compromissos econômicos, a relação com a cultura, a função simbólica conferida a sua atividade, tudo influenciando tempo e trajetória escolar (BOURDIEU, 1987).

Quanto ao tempo, estabeleceram-se diferenças a respeito dos modos de apropriação do chamado capital escolar. Na concepção de Bourdieu (1987), o volume acumulado pela família implica um tempo que antecede os filhos; não depende deles, mas condiciona suas trajetórias. Ao depender da família, a criança pode dedicar-se à formação escolar por tempo maior ou, do contrário, terá de submeter-se às condiçóes concretas da família, com relação ao tempo de entrada e permanência na escola.

Historicamente, percebemos que as condiçôes sociais de se manter o indivíduo na escola foram construídas à medida que liberaram as crianças do trabalho, com medidas protetivas e construção de políticas sociais e leis. Novamente, foi a força da lei que estabeleceu o tempo da infância, da escola e do respeito à criança, embora práticas sociais concretas ainda estejam distantes e não se efetivem totalmente.

Tanto na Argentina como no Brasil, tais preocupaçóes remetem ao início do século XX, quando se aprovaram leis para normatizar as condições de crianças no trabalho.

Na Argentina, a Lei no 11.317, de 1924, no seu artigo 1º, pregava: "Queda prohibido en todo el territorio de la República, ocupar a menores de 12 años de edad, en cualquier clase de trabajo, por cuenta ajena, incluso los trabajos rurales". (ARGENTINA, 1924).

No Brasil, "em fins de 1910, a Lei Federal no 1.596/1917 estabelecia, de fato, a idade de 12 anos como limite para admissão de mão de obra menor" (MOURA, 1999, p. 272).

Esses antecedentes históricos são importantes para não incorrermos no risco de conceber o tempo nem a trajetória da escolarização 
da infância como separados de outros contextos sociais. São, pois, as diversas infâncias e seus contextos que indicam os modos de atendimento institucional. Quanto a isso, acreditamos que crianças e adultos vivem experiências múltiplas e, na maioria das vezes, não ficam restritos somente às condições econômicas, mas se regulam também pelos padrões das práticas culturais, sociais e históricas, em cada grupo.

As diferenças de capital cultural das famílias implicam, em primeiro lugar, as diferenças de tempo entre o início da transmissão e a acumulação dos conhecimentos e da cultura. Em segundo lugar, nas diferenças da capacidade de satisfazer às exigências, propriamente culturais, de uma educaçáo prolongada, exigindo tempo, dedicação e certas condiçóes que não são extensivas a todos os indivíduos.

A educação infantil nos dois países está sujeita às demandas familiares e sociais por instituiçóes de atendimento. As famílias, em diferentes contextos, definem o momento de enviar a criança para a instituição. Podemos dizer que a passagem da criança para a escola depende das configuraçóes e das condiçóes institucionais e familiares, e esse tempo pode ser abreviado ou estendido.

Embora as desigualdades educativas e institucionais existam, elas não podem ser explicadas somente pelos obstáculos econômicos que atravessam os diferentes setores sociais, mas se esclarecem também por fatores culturais que se traduzem em atitudes e estratégias, mais ou menos conscientes, que levam a marca da origem social da criança.

Temos o exemplo da (noçáo de) meritocracia ou da teoria dos dons naturais, que são discursos nos quais os grupos mais favorecidos encontram legitimação para os seus privilégios culturais, transmitidos pela herança social e interpretados como fruto de talento individual ou mérito pessoal. Tais discursos contribuem para o disciplinamento das expectativas subjetivas de setores menos favorecidos, limitando suas perspectivas de acesso a espaços socais que são direito de todos, como a universidade, o tempo final da escolarização (KAPLAN, 2008).

Enquanto, para os setores desfavorecidos, a educaçáo superior parece impossível, para os mais bem posicionados esse espaço social é percebido como um caminho natural que se lhes abre por mérito. A eficácia simbólica desse processo de natureza perversa reforça o ocultamento 
dos vínculos que existem entre a ordem social e o sistema de classificação escolar. Bourdieu (1987) chamou de habitus tais disposiçóes duráveis, que tanto implicam uma memória social como garantem as práticas por longo tempo.

O fato de esse tempo escolar aprendido e de seu processo de continuidade parecer naturalizado pode ser creditado ao habitus, ou segunda natureza, que, para Elias (1994), constitui-se nas relaçóes entre a sociogênese, impressa nos grupos sociais, e a psicogênese individual. Esta, por sua vez, se constrói por meio da apreensão dos conceitos vividos em determinados contextos, passando estes — os conceitos - a ser parte do indivíduo que os utiliza sem questioná-los:

A história coletiva neles se cristalizou e ressoa. Porque lhes parece natural, porque desde a infância aprendem a ver o mundo através das lentes destes conceitos. [...] Uma geração os transmite a outra sem estar consciente do processo como um todo, e os conceitos sobrevivem enquanto esta cristalização de experiências passadas e situaçóes retiver um valor existencial, uma função na existência concreta da sociedade. (ELIAS, 1994, p. 260).

Nas sociedades ocidentais, especialmente brasileiras e argentinas, a infância ocorre na primeira década de vida do indivíduo. Entre 10 e 12 anos, as crianças estáo totalmente inseridas no contexto escolar, inclusive por força da lei, independentemente do que as famílias desejam para elas. Ao declarar como obrigatória a entrada da criança aos 5 ou 6 anos na educação básica, o Estado cria mecanismos para o seu ingresso, mas não garante a sua permanência.

Esse fenômeno ocorre nos dois países, especialmente se considerarmos os contextos em que as relaçóes institucionais e familiares se desenvolvem. A instituição escolar e sua organização, muitas vezes, não favorecem a ascensão nem a continuidade da formaçáo escolar de crianças e adolescentes. Seu sistema, fundado em tempos, rotinas, calendários, projetos curriculares, estrutura física, sistemas de avaliação e práticas pedagógicas, incide sobre o tempo de permanência da criança na escola, funcionando como limitador que de algum modo seleciona alguns e exclui outros. 


\section{TEMPO DE PARAR}

"Não deveria mais ser chamado. Quieto, ocupei-me até o toque da sineta. Mas foi tudo em vão" (BENJAMIM, 1993, p. 8384). Com um fragmento da nossa epígrafe, gostaríamos de propor algumas reflexốes breves, a título de continuidade da investigação, que não se esgota aqui.

Lembrando o que Benjamim nos instiga a pensar, ao apresentar uma criança sujeita ao tempo social aprendido, podemos falar de um tempo previsto pelos adultos e seus antecedentes (pais, famílias, professores) que vivem na perspectiva do tempo kronos, o tempo do relógio, do calendário, do disciplinamento do corpo e das açóes. No entanto, a despeito da normatização, crianças e adultos vivem em tempos distintos.

Poderíamos intuir que as crianças vivem o tempo kairós, tentando vivenciar o tempo fortuito, do imprevisto, do extraordinário, pelo qual elas se interessam. Suas relaçóes com o tempo aproximam-se das mediaçóes em sociedades ancestrais mais simplificadas, como ensina Elias (1998a), porém, à medida que a criança aprende, as relaçóes vão se complexificando, e ela passa a controlar e autocontrolar suas açóes em função do tempo social construído e precisa apreendê-las.

Em uma infância escolarizada, a criança necessita aprender sobre o tempo do calendário, do relógio, e deve se adaptar a ele. Voltandonos a Benjamin (1993, p. 84), no fragmento citado: "Quieto, ocupei-me até o toque da sineta", isto é, trabalhando de modo a cumprir as tarefas, procurando - "quieto" - não chamar a atenção e intentando obedecer às regras, às rotinas e à disciplina escolar. Por outras palavras: tempo de submeter-se aos símbolos e aos modos de ser da escola e dos adultos.

Portanto, se discutimos tempo e escolarização na infância, todos esses determinantes são importantes, pois o tempo não é igual para adultos e crianças, nem para professores e alunos. Ficar quieto, adaptar-se, submeter-se, obedecer são açôes que, para crianças e adolescentes, estão sendo requeridas, muitas vezes sem levar em conta todos os contextos e as condiçóes vividos por elas. Todavia, elas necessitam acomodar-se para sobreviver no espaço escolar, pois este é considerado o locus de transmissão de saberes e conhecimentos formais de uma geração à outra. 
Diferentemente da família e dos grupos de parentesco, a escola é um lugar de diversidade e desigualdades sociais, fundando-se em modelos que não incluem todas as crianças igualmente. Contudo, configuram-se em espaços regulados, mediante leis, decretos e todo um arcabouço legal que normatiza a trajetória e o cotidiano de todos seus integrantes.

No caso deste artigo, tanto no Brasil como na Argentina, criamos um ordenamento legal que levam em consideração muitas mudanças e lutas democráticas, em contextos de longa duração, mas ainda estamos longe de construirmos uma escola que compreenda crianças e adolescentes, com suas percepçóes temporais, sua especificidade e liberdade.

Finalizando, ao abordar o tema do tempo na escolarização e na constituição da infância, essa reflexão objetivou contribuir com o estudo das infâncias latino-americanas, especialmente as crianças brasileiras e argentinas, para quem desejamos uma educação emancipadora, com a perspectiva de viver um tempo mais democrático e plural, no qual viver as diversas infâncias seja possível.

\section{REFERÊNCIAS}

ARGENTINA. Ley n. ${ }^{\circ}$ 26.206, de 14 de dezembro de 2006. Ley de Educación Nacional. 2006. Disponível em: <http://www.coneau.edu.ar/archivos/1441.pdf>. Acesso em: 13 out. 2016.

. Gobiernodela Provinciade Buenos Aires. Secretaría de Derechos Humanos. Leyn. ${ }^{\circ}$ 26.061, de 21 de octubre de 2005. Ley de Protección Integral de los Derechos de las Niñas, Niños y Adolescentes. 2005. Disponível em: <http://www.ilo. org/dyn/travail/docs/1635/nacley26061 protecintegderechosniniosadolescpdf>. Acesso em: 17 out. 2016.

. Ministerio del Interior. Ley n. ${ }^{\circ} 11.317$, de 30 de septiembre de 1924. Regula el trabajo de las mujeres y los niños. 1924. Disponível em: <http://servicios.infoleg.gob.ar/ infolegInternet/anexos/190000-194999/194070/norma.htm>. Acesso em: 14 out. 2016.

Ley n. ${ }^{\circ}$ 20.744, de setembro de 1974. Ley de Contrato de Trabajo. 1974.

Disponível em: <http://www.ley20744argentina.com.ar/titulo-vii/capitulo-ii.html>. Acesso em: 17 out. 2016.

BENJAMIM, W. Rua de mão única. 3. a ed. São Paulo: Brasiliense, 1993. (Obras Escolhidas, v. 2). 
BOURDIEU, P. El espiritu de familia en razones prácticas. Sobre la teoría de la acción. Barcelona: Anagrama, 1997.

. Los tres estados del capital cultural. Sociológica, Buenos Aires, n. 5, 1987.

BRASIL. Constituição da República Federativa do Brasil. Brasília: Senado Federal, 1988. $292 \mathrm{p}$.

- Presidência da República. Casa Civil. Subchefia para Assuntos Jurídicos. Lei n. ${ }^{\circ}$ 8.090, de 13 de julho de 1990. Dispóe sobre o Estatuto da Criança e do Adolescente e dá outras providências. Brasília, 13 jul. 1990. Disponível em: $<\underline{\text { https:// }}$ www.planalto.gov.br/ccivil 03/leis/L8069.htm>. Acesso em: 12 out. 2016.

- Presidência da República. Casa Civil. Subchefia para Assuntos Jurídicos. Lei n. ${ }^{\circ}$ 9.394, de 20 de dezembro de 1996. Estabelece as Diretrizes e Bases da Educação Nacional. Brasília, 20 dez. 1996. Disponível em: <http:// www.planalto.gov.br/ccivil 03/leis/L9394.htm>. Acesso em: 13 out. 2016.

- Presidência da República. Casa Civil. Subchefia para Assuntos Jurídicos. Lei n. ${ }^{\circ} 11.274$, de 6 de fevereiro de 2006. Altera a redaçáo dos artigos 29, 30, 32 e 87 da Lei n. 9.394 de 20 de dezembro de 1996, que estabelece as Diretrizes e Bases da Educação Nacional, dispondo sobre a duração de 9 (nove) anos para o ensino fundamental, com matrícula obrigatória a partir dos 6 (seis) anos de idade. Brasília, 6 fev. 2006. Disponível em: <http://www.planalto.gov. br/ccivil_03/_ato2004 2006/2006/lei/111274.htm>. Acesso em: 13 out. 2016.

. Presidência da República. Casa Civil. Subchefia para Assuntos Jurídicos. Lei n. ${ }^{\circ}$ 11.770, de 9 de setembro de 2008. Cria o Programa Empresa Cidadá, destinado à prorrogaçáo da licença-maternidade mediante concessão de incentivo fiscal, e altera a Lei n. ${ }^{\circ}$ 8.212, de 24 de julho de 1991. Brasília, 9 set. 2008. Disponível em: <http:/www.planalto.gov.br/ccivil_03/_ato2007-2010/2008/ lei/l11770.htm>. Acesso em: 12 out. 2016.

ELIAS, N. O processo civilizador. Rio de Janeiro: Jorge Zahar, 1994.

. Sobre o tempo. Rio de Janeiro: Jorge Zahar, 1998a.

. La civilización de los padres. In: WEILLER, V. (Org.) La civilización de los padres y otros ensayos. Bogotá: Editorial Norma, 1998b. p. 407-450.

HADDAD, F.; FILMUS, D. Brasil-Argentina: o papel da educaçâo na aliança estratégica. 2005. Disponível em: <http://portal.mec.gov.br/arquivos/pdf/artigo haddad filmus.pdf>. Acesso em: 13 out. 2016. 
KAPLAN, C.V. Talentos, dones e inteligencias. El fracaso escolar no es un destino. Buenos Aires: Colihue, 2008.

LAHIRE, G.V.; THIN, D.B. Sobre a história e a teoria da forma escolar. Educação em Revista, Belo Horizonte, v. 33 p. 7-48, jun. 2001. Disponível em: $<$ http://www. piraquara.pr.gov.br/aprefeitura/secretariaseorgaos/educacao/uploadAddress/>. Acesso em: 15 out. 2016.

MELLO, S.B.M. A Prorrogação da Licença Maternidade. Lei n.o 11.770, de 9 de setembro de 2008. Disponível em: <http:/www.calvo.pro.br/media/file/colaboradores/ simone mello/simone mello prorrogacao licenca.pdf. . Acesso em: 15 out. 2016.

MOURA, E.B. As crianças operárias na recém-industrializada. São Paulo. In: DEL PRIORE, M. (Org.). Histórias das crianças no Brasil. São Paulo: Contexto, 1999.

OLIVEIRA, L.C.V.; SARAT, M. Educação Infantil: história e gestão educacional. Dourados: Editora da UFGD, 2009.

Recebido em 14 de janeiro de 2017. Aprovado em 24 de junho de 2017. 